\title{
Novel Guidelines for Immunotherapeutic Treatment Options of Genital Warts: Review article
}

\author{
Shimaa Mohamed Abd Elfatah, Eman Abd Elgawad Nofal, Soheir Mohamed Ghonemy \\ Dermatology, Venereology and Andrology Department, Faculty of Medicine, Zagazig University, Egypt. \\ Corresponding Author: Shimaa Mohamed Abd Elfatah, Email: shimaaemam3@gmail.com
}

\begin{abstract}
Background: The appearance of genital warts varies. Flat or resembling raspberries or cauliflower, they can be found in a variety of shapes. They begin as little red or pink growths and can reach a diameter of four inches or more before interfering with sexual activity or delivery (in certain circumstances) (in some cases). The warts thrive in the vaginal area's moist tissues. On the external genitals and the walls of the cervix and urethra, in women, as well as on the shaft of the penis in males, they are found. Despite the availability of different therapeutic modalities, treating warts with immunotherapy is a tremendous benefit. HPV vaccination has shown promising efficacy in the treatment of genital warts. Objective: To hallmark the new guidelines of immunotherapeutic options for treatment of genital warts. Conclusion: Immunotherapy with HPV vaccines is an effective and safe treatment modality of anogenital warts.

Keyword: Genital warts, Immunotherapy, HPV vaccination.
\end{abstract}

\section{INTRODUCTION}

Anogenital wart, most sexually transmitted infections are caused by the anogenital human papilloma virus (HPV), which can cause cancerous or noncancerous skin and mucosal tumors, including anogenital warts (AGWs) to occur. To qualify as an anogenital HPV infection, AGWs must have visible lesions on the perianal area, vulva, urethra, perianal area and urethra. These lesions include single or numerous papules ${ }^{(\mathbf{1})}$.

Condylomata acuminata (pointed warts), flat/macular lesions, papular lesions, and keratotic lesions are all subtypes of AGWs that have been documented. The first two varieties are often seen on wet, non-keratinized epithelia, whereas the latter two are more commonly found on keratinized epidermis. However, genital warts (GWs) and genital verruca are really subclasses of the AGW group ${ }^{(2)}$.

The majority of AGW cases are caused by HPV 6 or 11. Infection with AGWs is extremely contagious, with roughly 65 percent of those infected developing AGWs within three weeks and eight months. Buschke Lowenstein tumours (BLTs) have been linked to AGWs in a small number of instances ${ }^{(3)}$.

Giant condyloma acuminatum, a fungating variety of condyloma, was first described by Buschke in 1896 and is extremely uncommon. One of condyloma's most virulent strains is this one. Depending on the aggressiveness of the lesion, several sinuses or fistula tracts can be formed, which can penetrate deep into the fascia, muscle, and rectum. Inflammation, infection, or bleeding may result from this. This benign lesion has a high recurrence rate and is difficult to treat because of its large size, local invasion, and recurrence potential ${ }^{(4)}$.

Aim of the study was to hallmark the new guidelines of immunotherapeutic options for treatment of genital warts.

\section{Immunotherapy:}

Genital warts can be treated in two ways: Aggressively and destructively using traditional methods such as, cryotherapy, electrocauterization, chemical cautery, laser ablation and surgical excision, or using immunotherapy to stimulate the immune system to fight the virus and reduce its activity. Intralesional, topically, or systemically, immunotherapy can be administered ${ }^{(5)}$.

Because of the availability of various therapeutic lines and the immune status of the patients, the selection of the most appropriate means of immunotherapy is usually difficult. Many factors should be considered before the treatment of the patients, such as age, sex, past medical history, and the clinical characteristics of warts. People who suffer from many warts or warts that are resistant to treatment are more likely to have a faulty cellmediated immune response ${ }^{(6)}$. Due to immunotherapy's ability to treat warts that are far from where they were injected, a large proportion of patients are cured of remote warts as a result of the treatment ${ }^{(7)}$. In genital wart treatment, immunomodulating drugs such as skin test antigens, interferon- $\alpha 2 b$ (IFN- $\alpha 2 b$ ), and topical imiquimod agents have been widely used ${ }^{(8)}$. Interleukin 6 (IL6), IL-1 $\beta$, tumor necrosis factor - $\alpha$ - and IFN- $\alpha$ are some of the cytokines that are elevated when imiquimod is applied topically. Other immunotherapy approaches that induce robust tissue cytokine responses should be investigated in light of the response of genital warts to them. Genital warts can be successfully treated with intralesional immunotherapy utilizing various antigens as MMR vaccination, trichophyton skin test antigens and candidal extract, mycobacterium $\mathrm{W}$ vaccine (MWV) and bacillus Calmette-Guérin (BCG) ${ }^{(9)}$ as shown in table (1).

A very promising immunotherapeutic option is vaccination with any of the HPV vaccines available for the prevention of cervical cancer. Vaccination seems to induce immunity to those HPV types that cause genital and extragenital cutaneous warts because of crossreactivity ${ }^{\mathbf{1 0})}$. 
Table (1): Genital warts can be treated with immunotherapy using a variety of medicines ${ }^{(11)}$

\begin{tabular}{|c|c|}
\hline Agent & Dose and administration \\
\hline \multicolumn{2}{|l|}{ Topical agents: } \\
\hline Imiquimod & $5 \%$ cream ,3times per weak,for 16 weeks \\
\hline BCG & $\begin{array}{l}\text { applied topically on warts in normal saline or salicylic acid, washed after } 2 \text { hours, } \\
\text { weakly treatment for 6-12 weeks }\end{array}$ \\
\hline \multicolumn{2}{|l|}{ Intralesional agents: } \\
\hline BCG vaccine & $0.1-0.5 \mathrm{ml}$ intralesional injection in largest wart, in 2 weaks interval for 5 sessions \\
\hline PPD & $0.1 \mathrm{ml}$ weakly intradermal injection in the forearm for 12 weaks \\
\hline Trichophyton antigen & $0.3 \mathrm{ml}$ injection in largest wart every 3 weeks, maximum 5 sessions. \\
\hline Interferon alfa 2B & 1-2 million units3days per weak(Monday-Wednesday- Friday)for 3 weeks \\
\hline MMR vaccine & $0.3-0.5 \mathrm{ml}$ into the single large wart for up to 5 sessions \\
\hline Candidal extract & $\begin{array}{l}0.1-0.3 \mathrm{ml} \text { injected in the largest wart in } 1^{\text {st }} \text { setting, then } 3 \text { weakly intralesional } \\
\text { injections }\end{array}$ \\
\hline Systemic Interferon & \\
\hline
\end{tabular}

Exactly how intralesional immunotherapy works has not yet been explained. This method of immunotherapy is expected to take advantage of the patient's capacity to create a delayed-type hypersensitivity response to wart tissue, and numerous antigens injected ${ }^{(12)}$. TH1 cytokines, which activate natural killer and cytotoxic T cells, are connected with this hypersensitive response. The "injected" warts may be cleared, but in certain circumstances, remote warts may also be cleared ${ }^{(13)}$.

The intralesional immunotherapy responders also exhibit a considerably positive peripheral mononuclear cell proliferation test compared to the non-responders. Several cytokines, including as interleukin (IL) 2, IL-4, IL-5, IL-8, IL-12, tumor necrosis factor alpha, and interferon-gamma are released during intralesional immunotherapy, which can generate a powerful immune response contrary to HPV. A certain type of host cellmediated immune response appears to be a necessity for immunotherapy to be successful (14).

Trichophyton keratolytic dermatophyte and Candida albicans proteins are two of the most commonly employed antigens for this purpose. MMR vaccination is another intralesional antigen injection method that is usually utilized for protection of measles, mumps, and rubella. MMR is a live attenuated vaccine that is more antigenic than individual antigen-based vaccines. Consequently, one might expect a significant immunological reaction ${ }^{(\mathbf{1 5})}$.

Genital warts treatment approaches might not entirely remove HPV cells. Additionally, the efficacy of these treatments in reducing the infectivity of HPVrelated lesions is still uncertain ${ }^{(16)}$. Genital warts and other cancers can be prevented in both sexes with the HPV vaccine. The concept of vaccination has recently been broadened to include the idea of its therapeutic use. It hasn't been formally approved in any country because it hasn't been tested in a randomized, prospective trial ${ }^{(\mathbf{1 7})}$.

A number of single-case studies have documented the efficacy of bivalent and quadrivalent HPV vaccinations in treating genital and persistent cutaneous warts. Cross-protection against HPV strains other than those targeted by the vaccination provided or the activation of lymphocytes targeting the virally infected cells may explain their therapeutic effect ${ }^{(\mathbf{1 8})}$.

Traditionally, the goal of vaccination has been to stimulate the body's immune system in order to fight off infection. Genital warts can be eliminated by HPV vaccine, which has a low risk of side effects, and people are better protected against HPV relapses ${ }^{(\mathbf{1 7})}$.

\section{HPV vaccine:}

Empty virus-like particles (VLP) derived from recombinant HPV capsid protein L1 are used to make vaccines for the HPV virus. Because they don't contain any living biological product or DNA, they are not contagious. Encouraging antibodies to neutralize and inhibit HPV entrance into cells is the primary goal of VLP $^{(19)}$.

The FDA has just approved the use of two new vaccines: Cervarix and Gardasil are the two most commonly prescribed vaccines in the United States. Gardasil has recombinant L1 VLPs for HPV genotypes $6,11,16$, and 18 whereas Cervarix is a bivalent vaccination that contains L1 VLPs for HPV-16 and HPV-18 in the quadrivalent vaccine. Nearly $90 \%$ of all cervical cancers globally might be prevented with the recently licensed nonvalent (9-valent) vaccination targeting HPV 6, 11, 16, 18 and five additional carcinogenic strains ${ }^{(20)}$.

Even though they have a lot of antigenic similarities, the vaccines are made using distinct methods and contain unique adjuvants. Aluminum hydroxyphosphate sulphate is used in the Gardasil vaccination, whereas AS04, which comprises aluminium hydroxide salts and the TLR4 agonist MPL (3-O-desacyl-4'monophosphoryl lipid A) is used in the Cervarix vaccine. Cervarix's greater immunogenicity may be due to the use of the AS04 adjuvant ${ }^{(21)}$. In 2006, the FDA approved Gardasil for use in girls aged from 9 to 26 years old. When Cervarix was authorised by the FDA in October 2009 , the agency also approved Gardasil for use in men aged from 9-26 to prevent the spread of cervical cancer. Cervical cancer rates may be affected by these recent occurrences ${ }^{\text {(22) }}$ (Table 2). 
Table (2): The Cervarix versus Gardasil comparisons ${ }^{(23)}$

\begin{tabular}{|c|c|c|}
\hline Category & Gardasil & Cervarix \\
\hline Included HPV strains & HPV $6,11,16,17$ & HPV $16 \& 18$ \\
\hline The system of production & Yeast & $\begin{array}{l}\text { Recombinant baculovirus } \\
\text { infected insect cells }\end{array}$ \\
\hline Addition & Alum & $\begin{array}{l}\text { Aluminum salt } \\
\text { monophosphoryl } \\
\text { (ASO4 + MPL) }\end{array}$ \\
\hline For diseases & $\begin{array}{l}\text { Cervical, vaginal, and anal } \\
\text { malignancies, as well as their } \\
\text { associated precancerous lesions (and } \\
\text { a subset of head and neck cancers) } \\
\text { Sexually transmitted infections such } \\
\text { as genital warts and laryngeal } \\
\text { papillomas }\end{array}$ & $\begin{array}{l}\text { Cervical, vulval, vaginal, and } \\
\text { anal cancers, as well as their } \\
\text { precursor lesions (including a } \\
\text { subset of head and neck } \\
\text { cancers), are all examples of } \\
\text { anogenital cancer) }\end{array}$ \\
\hline $\begin{array}{l}\text { Data about the duration of } \\
\text { protection are readily available. }\end{array}$ & Minimum 5 years & 5.5 years \\
\hline Dose & $\begin{array}{l}0.5 \mathrm{~mL} \text { dose containing } 20 \mu \mathrm{g} \text { HPV6 } \\
\mathrm{L} 1,40 \mu \mathrm{g} \text { HPV } 11 \mathrm{~L} 1,40 \mu \mathrm{g} \text { HPV } 16 \\
\mathrm{~L} 1, \text { and } 20 \mu \mathrm{g} \text { HPV } 18 \mathrm{~L} 1\end{array}$ & $\begin{array}{l}0.5 \quad \mathrm{~mL} \text { dose } \\
20 \mu \mathrm{g} \text { HPV } 16 \quad \text { L1 and } \\
20 \mu \mathrm{g} \text { HPV18 L1 }\end{array}$ \\
\hline $\begin{array}{l}\text { Suggestions on how to } \\
\text { administer The route and the } \\
\text { routine }\end{array}$ & $\begin{array}{l}\text { At } 0 \text { days, } 2 \text { months, and } 6 \text { months, } \\
\text { receive three intramuscular shots. }\end{array}$ & $\begin{array}{l}\text { At } 0,1 \text {, and } 6 \text { months, three } \\
\text { intramuscular doses are } \\
\text { administered. }\end{array}$ \\
\hline age group of vaccination & Nine to twenty-six & Ten to twenty-five \\
\hline
\end{tabular}

\section{MECHANISM}

The L1 and/or L2 viral capsid proteins are encoded by HPV virus-like particles (VLPs) in preventive HPV vaccinations. There is a strong emphasis on humoral immunity in HPV vaccinations. The HPV VLPs attach to B cells and TH2 activates them. In order to develop into plasma cells that produce antibodies. As a result of these antibodies, the body is protected from HPV infection ${ }^{(24)}$.

\section{CONCLUSION}

Immunotherapy with HPV vaccines is an effective and safe treatment modality of anogenital warts.

\section{Financial support and sponsorship: Nil. Conflict of interest: Nil.}

\section{REFERENCES}

1. Gross G, Pfister H (2004): Role of human papillomavirus in penile cancer, penile intraepithelial squamous cell neoplasias and in genital warts. Medical Microbiology and Immunology, 193 (1): 35-44.

2. Patel H, Wagner M, Singhal P et al. (2013): Systematic review of the incidence and prevalence of genital warts. BMC Infectious Diseases, 13 (1): 1-14.

3. Giuliano A, Tortolero-Luna G, Ferrer E et al. (2008). Epidemiology of human papillomavirus infection in men, cancers other than cervical and benign conditions. Vaccine, 26: 17-28.
4. Renzi A, Giordano P, Renzi G et al. (2006): BuschkeLowenstein tumor successful treatment by surgical excision alone: a case report. Surgical Innovation, 13 (1): 69-72.

5. El-Khalawany M, Shaaban D, Aboeldahab S (2015): Immunotherapy of viral warts: myth and reality. Egyptian Journal of Dermatology and Venerology, 35 (1): 1-5.

6. Allen A, Siegfried E (2001): Management of warts and molluscum in adolescents. Adolescent Medicine Clinics, 12 (2): 229-233.

7. Aldahan A, Mlacker S, Shah V et al. (2016): Efficacy of intralesional immunotherapy for the treatment of warts: A review of the literature. Dermatologic Therapy, 29 (3): 197-207.

8. McMillan A (1999): The management of difficult anogenital warts. Sexually Transmitted Infections, 75 (3): 192-196.

9. Gupta S, Malhotra A, Verma K et al. (2008): Intralesional immunotherapy with killed Mycobacterium $\mathrm{w}$ vaccine for the treatment of ano-genital warts: an open label pilot study. Journal of the European Academy of Dermatology and Venereology, 22 (9): 1089-1093.

10. Abeck D, Tetsch L, Lüftl M et al. (2019): Extragenital cutaneous warts-clinical presentation, diagnosis and treatment. Journal der Deutschen Dermatologischen Gesellschaft, 17 (6): 613-634.

11. Thappa D, Chiramel $M$ (2016): Evolving role of immunotherapy in the treatment of refractory warts. Indian Dermatol Online J., 7 (5): 364-75. 
12.Goihman-Yahr M, Goldblum O (2008): Immunotherapy and warts: a point of view. Clinics in Dermatology, 26 (2): 223-225.

13. Na C, Choi H, Song $S$ et al. (2014): Two-year experience of using the measles, mumps and rubella vaccine as intralesional immunotherapy for warts. Clinical and Experimental Dermatology, 39(5): 583-589.

14. Kus S, Ergun T, Gun D et al. (2005): Intralesional tuberculin for treatment of refractory warts. Journal of the European Academy of Dermatology and Venereology, 19 (4): 515-516.

15. Awal G, Kaur S (2018): Therapeutic outcome of intralesional immunotherapy in cutaneous warts using the Mumps, Measles, and Rubella vaccine: A randomized, placebo-controlled Trial. The Journal of Clinical and Aesthetic Dermatology, 11 (5): 15-19.

16. Yang A, Farmer E, Wu T et al. (2016): Perspectives for therapeutic HPV vaccine development. Journal of Biomedical Science, 23 (1): 75-79.

17. Choi H (2019): Can quadrivalent human papillomavirus prophylactic vaccine be an effective alternative for the therapeutic management of genital warts? An exploratory study. International Braz J Urol., 45: 361368.
18. Ferguson S, Gallo E (2017): Nonavalent human papillomavirus vaccination as a treatment for warts in an immunosuppressed adult. JAAD Case Reports, 3 (4): 367-369.

19. Cutts F, Franceschi S, Goldie S et al. (2007): Human papillomavirus and HPV vaccines: a review. Bulletin of the World Health Organization, 85: 719-726.

20.Saraiya M, Unger E, Thompson T et al. (2015): US assessment of HPV types in cancers: implications for current and 9-valent HPV vaccines. Journal of the National Cancer Institute, 107 (6): 1-5.

21.Herrin D, Coates E, Costner $P$ et al. (2014): Comparison of adaptive and innate immune responses induced by licensed vaccines for Human Papillomavirus. Human Vaccines and Immunotherapeutics, 10 (12): 3446-3454.

22. Ma B, Roden R, Wu T (2010): Current status of HPV vaccines. Journal of the Formosan Medical Association, 109 (7): 481-486.

23. Monie A, Hung $C$, Roden $R$ et al. (2008): Cervarix ${ }^{\mathrm{TM}}$ : a vaccine for the prevention of HPV 16, 18-associated cervical cancer. Biologics: Targets and Therapy, 2 (1): 107-111.

24. Lin K, Doolan K, Hung C et al. (2010): Perspectives for preventive and therapeutic HPV vaccines. Journal of the Formosan Medical Association, 109 (1): 4-24. 